\title{
A FORMAÇÃO DOCENTE NO BRASIL: HISTÓRIA E POLÍTICA
}

Considero o tema desta Mesa Redonda - A formação docente no Brasil: História e Política - bastante complexo, dada a sua amplitude e a dificuldade de tratá-lo adequadamente com a devida abrangência.

Essa dificuldade é tanto maior quando se considera que nas duas últimas décadas o movimento de pesquisa sobre a formação de professores se ampliou consideravelmente, inclusive com mudança na orientação teórica e no foco de análise. O movimento de profissionalização do ensino que se desenvolveu a partir dos EUA e que atua no sentido de constituição de uma base de conhecimentos profissionais para o ensino, acabou por levar à multiplicação de estudos e pesquisas sobre a profissionalização docente, sobre os saberes dos professores, sobre a prática profissional como fonte, local de formação e de construção de saberes, sobre a identidade do professor, sobre a formação como processo permanente, que envolve a formação inicial e a continuada (ANDRÉ, 1999; NUNES, 2001).

Essa ampliação da pesquisa é acompanhada de uma série de reformas nos vários países, inclusive no Brasil. Tais reformas introduzem grandes modificações nos sistemas de formação, para todos os níveis de ensino, que permaneciam quase inalterados em sua estrutura geral desde os anos trinta do século passado.

A principal alteração é, a meu ver, o tratamento único e a adoção de uma medida comum para a formação de professores para todo o ensino básico, estabelecendo-se que essa formação "far-se-á em nível superior, em curso de licenciatura, de graduação plena, em universidades e institutos superiores de educação". (Lei 9394/

Professora de História da Educação Brasileira no Programa de Pós-Graduação em Educaçāo da Faculdade de Filosofia e Ciências de Marília/UNESP 
96, art. 62) Apenas a formação de professores para o ensino superior permanece com tratamento à parte, ou seja, em nível de pós-graduação, prioritariamente em programas de mestrado e doutorado (Lei 9394/96, art.66).

A mencionada medida é bastante relevante, se considera que os cursos de formação para os diversos níveis e modalidades de ensino nasceram completamente divorciados entre si, em instituições diferentes e com currículos diversos. O preparo dos docentes para as séries iniciais da escola básica fez-se tradicionalmente no Brasil, em escolas normais, surgidas no século XIX em nível de modestas escolas primárias e paulatinamente elevadas ao nível médio. Centradas inicialmente no conteúdo a ser ensinado, acrescido de "Pedagogia" e "Exercícios Práticos de Ensino", essas escolas foram aos poucos incorporando o ideário escolanovista, que as marcaria definitivamente, com seu embasamento nas "Ciências da Educação" e sua ênfase na psicologia das diferenças individuais, nos aspectos técnicos pedagógicos, na metodologia do ensino, na "derivação" científica e na suposta neutralidade dos procedimentos didáticos. A partir dos anos trinta vai-se consolidando um modelo que persistiria, em linhas gerais, praticamente até a Lei 5692/71, e que consistiu em substituição do conteúdo de formação geral pelo primeiro ciclo do curso secundário. Assim, a preocupação central do currículo da EN desloca-se dos "conteúdos" a serem ensinados para os métodos e processos de ensino, valorizando-se as chamadas "ciências da educação", principalmente as contribuições da Psicologia e da Biologia. Reformas pioneiras nesse sentido foram realizadas inicialmente no Distrito Federal, por Anísio Teixeira, em 1932, e no Estado de São Paulo em 1933, por Fernando de Azevedo, estendendo-se, paulatinamente, a outros estados. Essa preocupação com a chamada formação pedagógica continuaria a predominar no currículo das escolas normais mesmo posteriormente, quando se sentiu a necessidade de ampliar a formação geral dos alunos, com a inclusão de conteúdos de formação geral.

Se esse foi o modelo consolidado para a formação dos professores para os anos iniciais da escolaridade, a formação específica de docentes para o ensino secundário nasceu muito mais tarde, na dé- 
cada de trinta, com a criaçào das Faculdades de Filosofia, Ciências e Letras, calcada num modelo que privilegiaria o conteúdo a ser ensinado, à semelhança do que se fazia em outros países. Assim, na Universidade do Distrito Federal, criada em 1935, a então chamada Faculdade de Educação concedia a "licença magistral" (a partir de uma formação pedagógica) àqueles que adquirissem na universidade a "licença cultural" (formação científica numa especialidade). Também com a criação da Universidade de São Paulo em 1934, uma Secção de Educação encarregava-se da formação pedagógica dos alunos egressos das diversas seç̧ões da Faculdade de Filosofia, Ciências e Letras que pretendessem licença para o magistério. ${ }^{2}$ Esse modelo de formação - que tem sido denominado de " $3+1$ " e que tem sido responsabilizado, nem sempre justamente a meu ver, pelas mazelas de nossa licenciatura - permaneceria na prática mesmo com a criação das Faculdades de Educação, a partir da Lei 5540/68. As pequenas mudanças ocorridas foram no sentido de tornar a formação pedagógica concomitante à formação específica na área. Em alguns casos, o discurso da especificidade da formação do professor chegou a levar à constituição de cursos paralelos - para o preparo de bacharéis e de licenciados - sem que, na verdade, esses cursos fossem, de fato, suficientemente específicos, a não ser pelas poucas disciplinas referentes à formação pedagógica, substituídas por disciplinas de aprofundamento para o bacharelado na área específica. A experiência da UNESP, universidade que possui 42 cursos de licenciatura, é bastante elucidativa a esse respeito. A maioria dos cursos específicos que se instalaram para a formação de licenciados e de bacharéis, acabaram por se integrar a partir de um tronco comum de currículo, de um lado para permitir maior flexibilidade e aproveitamento de estu-

\footnotetext{
Abrindo um parênteses, gostaria de destacar que os cursos de formação pedagógica de nível superior, tanto da UDF como da USP, tiveram origem nas escolas normais das cidades do Rio de Janeiro e de São Paulo, então denominadas de Institutos de Educação, com a transferência temporária de sua Escola de Professores para a Universidade. Alguns autores relacionam a essa origem o desprestígio dos estudos superiores de educação, ou seja, ao fato de que seus primeiros docentes eram antigos professores do curso normal, elevados, com suas "cadeiras", ao nível superior.
} 
dos e, de outro, pela falta de especificidade nos currículos de bacharelado e da licenciatura.

Apesar das alterações introduzidas com as reformas do regime militar - Lei 5540/68 e 5692/71, os modelos de cursos de formação de professores para as séries iniciais e para as séries posteriores da escolaridade pouco se alteraram, permanecendo esses cursos independentes e sem qualquer articulação. A legislação continuava a prever o diploma de segundo grau para a docência até a $4^{\text {a }}$. série do $1^{\circ}$ grau e a licenciatura plena para o exercício até o final do segundo grau, os primeiros formando professores polivalentes, com ênfase na formação pedagógica, e os segundos formando docentes especialistas por área e por disciplina, com ênfase no conteúdo objeto de ensino.

$\mathrm{Na}$ verdade, as grandes alterações ocorreram não por conta da legislação ou de uma política previamente definida, mas por conta da prática pedagógica concreta que ocorre no interior das escolas e das conquistas consolidadas ao longo do caminho percorrido. Assim, no que diz respeito à formação do professor para as séries iniciais, a descaracterização das escolas normais decorrente das medidas introduzidas com a Lei 5692, a conseqüente queda das matrículas na Habilitação Magistério e o descontentamento relativamente à desvalorização da profissão acabaram por levar a um movimento em âmbito estadual e federal, com discussão de projetos de estudos, pesquisas e propostas de ação freqüentemente denominados de "revitalização do ensino normal", propiciando iniciativas no sentido de propor medidas para reverter o quadro instalado. Entre essas medidas devem ser destacadas a criação dos CEFAMs, que se estenderam por todo o país, e que incorporaram "medidas especiais" já historicamente reivindicadas; os esforços de várias Secretarias Estaduais no sentido de melhorar o currículo, resgatar a especificidade do curso, incorporar medidas introduzidas nos CEFAMs e, finalmente, os esforços de unidades escolares no sentido de melhorar a prática desenvolvida a partir do coletivo de seus professores.

Ainda quanto ao esforço desenvolvido para melhorar a formação de professores para as séries iniciais, deve ser acrescentada a progressiva remodelação pela qual passou o Curso de Pedagogia a partir dos anos 80 , de modo a adequar-se progressivamente a essa tarefa, a 
qual, aliás, já vinha desempenhando sem estar devidamente aparelhado. Aos poucos, esses cursos foram incorporando a Teoria e a Prática do Ensino de Primeiro Grau, na habilitação Magistério para o ensino de $2^{\circ}$ Grau. Essa habilitação passou a visar também ao preparo dos professores para as séries iniciais, conforme aliás possibilitava o próprio Parecer CFE 252/69 e, em alguns casos, criaram-se habilitações específicas para esse fim, o.que motivou um esforço para ampliação das disciplinas de instrumentação, diversificando-as, de modo a cobrir os diversos componentes curriculares dos anos iniciais da escolaridade. Entretanto, esses cursos não parecem ter ganhado o reconhecimento necessário como instância responsável pela formação de profissionais para os anos iniciais da escola básica.

Quanto à formação de professores para as séries finais da escola básica, feita nos cursos de licenciatura, cumpre destacar que a problemática desses cursos permaneceu a mesma desde a sua origem nas antigas Faculdades de Filosofia até o presente, conforme, aliás, indicam as pesquisas (CANDAU, 1998). Sistematicamente registrase a falta uma proposta integrada, de articulação entre o conteúdo específico e o pedagógico e entre a teoria e a prática. As tentativas de integração desenvolvidas reduziram-se, no mais das vezes, a substituir uma relação de sucessão por uma relação de concomitância mais adequada entre o conteúdo específico e o pedagógico. Ademais, o conteúdo pedagógico permaneceu praticamente o mesmo ao longo dos anos, limitando-se ao mínimo fixado pelo CFE: Psicologia, Didática, Estrutura e Funcionamento do Ensino ou Política Educacional e Prática de Ensino.

Essa é, em síntese e em traços rápidos, a situação encontrada pela Lei 9394/96 no que tange à formação de professores: uma diversidade de instituições formadoras, seja em nível médio, seja em nível superior, com predominância das de nível médio, sobretudo as de iniciativa pública. Assim, em 1996, havia 5276 Habilitações Magistério em estabelecimentos de ensino médio, das quais $3420 \mathrm{em}$ escolas estaduais, 1152 em escolas particulares, $761 \mathrm{em}$ municipais e 3 federais. Quanto aos cursos de Pedagogia, dados de 1994 indicavam a existência de apenas 337 em todo o país, 239 dos quais de iniciativa particular, 35 federais, 35 estaduais e 28 municipais. Além da 
vinculação predominante desses cursos à iniciativa privada, observa-se também a sua grande concentração na região sudeste, onde se localizavam 197 cursos, 165 deles pertencentes à iniciativa particular. (TANURI, 2000) Assim, tais dados não reforçavam a idéia de adoção do modelo único de formação em nível superior.

Nesse quadro referencial, a nova Lei de Diretrizes e Bases (Lei 9394/96) estabelece que "a formação de docentes para atuar na educação básica far-se-á em nível superior, em curso de licenciatura, de graduação plena, em universidades e institutos superiores de educação..." (art. 62) Assim, o legislador optava por inserir uma nova instituição no panorama educacional, provavelmente por inspiração dos Institutos Universitários de Formação de Mestres (IUFM) franceses, que forneceram referencial para a experiência realizada no país. Ao mesmo tempo, parecia que se desconsiderava a trajetória recente dos cursos de Pedagogia e a sua progressiva orientação com vistas ao preparo do pessoal docente para a educação infantil e para os anos iniciais da escolaridade. De conformidade com o art. 63 da nova LDB, os Institutos Superiores de Educação(ISE) deverâo manter "cursos formadores de profissionais para a educação básica, inclusive o curso normal superior, destinados à formação de docentes para a educaçào infantil e para as primeiras séries do ensino fundamental." Apesar de estabelecer como norma a formação em nivel superior, a Lei admite como formaçào mínima a oferecida em nível médio, nos cursos normais. Isso faz supor, dada a realidade existente, que tais cursos deverão subsistir ainda por muito tempo, embora fique estipulado nas disposiçōes transitórias um prazo de apenas dez anos para essa formação.

A Lei é seguida de uma série de documentos legais, sobretudo Decretos, Pareceres e Resoluçōes pertinentes ao assunto, determinando medidas diversas, entre elas: a prioridade dos ISEs e de seus Cursos Normais Superiores no preparo de docentes para a educação infantil e para as séries iniciais do ensino fundamental; o impedimento dos cursos de Pedagogia de IES não-universitárias de atuar no mesmo sentido; a utilização da educação à distância ou de seus recursos para agilizar (e aligeirar?) a formação inicial; a ênfase nos aspectos práticos da formação nas licenciaturas ditas de conteúdo; a separa- 
ção entre as licenciaturas e os bacharelados; a ênfase na especificidade dos cursos de licenciatura e, ao mesmo tempo, a valorização dos programas especiais de formação para profissionais não-docentes que, de certa forma, negam a aludida especificidade.

A multiplicidade de questões controvertidas é grande, não havendo possibilidade de discutir, no limite de tempo destinado a esta mesa-redonda, as deficiências e as possibilidades das políticas adotadas e suas eventuais conseqüências. Em tais circunstâncias, gostaria de fazer alguns destaques, priorizando questões de meu maior interesse.

1) Embora já esteja estabelecido que a formação de professores para atuação multidisciplinar - da educação infantil e das séries iniciais do ensino fundamental - deva ocorrer preferencialmente nos denominados Cursos Normais Superiores, no interior dos Institutos Superiores de Educação, essa orientação não é obrigatória para as universidades e centros universitários, que poderão continuar ofertando tal formação nos Cursos de Pedagogia, vinculados seja às suas Faculdades ou aos seus Centros de Educação, desde que obedecidas as respectivas diretrizes curriculares (Parecer CES/CNE 133/ 2001). Não há dúvida de que essa evidente superposição entre o Curso de Pedagogia e o Curso Normal Superior e entre as Universidades/Faculdades de Educação e os Institutos Superiores de Educaçào vem causando grande polêmica e radicalização de posições, quanto ao local e quanto à natureza da formação a ser ministrada. (Freitas, 1999; Silva, W.C., 1999; Weber 2000). Em tais circunstâncias, acredito que o CEE de São Paulo agiu bem ao estabelecer a organização dos 1SEs, para as instituições isoladas de seu sistema, com carúter experiinental, nos termos do art. 81 da LDB, caráter esse que significa o ensaio de novas possibilidades de formação docente, ao invés de optar por um modelo padronizado. Esse ensaio de novas possibilidades deverá ser feito com base na autonomia da escola e a partir de um projeto institucional que congregue esforços de três instâncias: das entidades mantenedoras; dos órgãos centrais da administração pública da educação (estadual ou municipal) e das universidades públicas. (Indicação CEE 7/2000; Del. CEE 08/2000 e Indicação CEE 21/ 2002). Entretanto, os intentos dos conselheiros ainda não parecem 
ter surtido o efeito desejado, pois as propostas inovadoras esperadas ainda não chegaram, ou, pelo menos, ainda não foram apreciadas, já que não se tem notícia delas.

Tudo indica que, apesar da conquista legal, a formação em nível superior continua a ser um desafio para os educadores, até porque a regulamentação dos Institutos Superiores de Educação (Res. CNE 01/ 99) tem trazido incertezas acerca de suas conseqüências para a qualificação de docentes. Embora se reconheça que eles podem ser um avanço nos locais onde inexistem cursos superiores de formação, por parte de educadores, de instituições de ensino superior e de associaçōes de docentes teme-se um nivelamento por baixo em face da ênfase numa formação eminentemente prática, desvinculada da possibilidade de pesquisa, e devido aos padrōes de qualificação docente inferiores àqueles exigidos nas universidades. Por outro lado, tendo em vista as conquistas positivas dos CEFAMs, a longa tradição das escolas normais e a extensa rede de habilitações de nível médio em estabelecimentos públicos, também se teme o simples desmonte de um sistema público e o enfraquecimento do compromisso do Estado para com a formação de professores. Acredito que só se poderá chegar a resultados positivos se a introdução das novas instituições não implicar a desmobilização pura e simples das atualmente existentes e na medida em que os ganhos já assegurados e a experiência já acumulada tanto pelos Cursos de Pedagogia como pela imensa rede pública de cursos médios de formação puderem ser capitalizados e aproveitados.

2) Um segundo ponto que eu gostaria de levantar diz respeito às licenciaturas ditas de conteúdo. O CNE mediante seus pareceres e resoluçōes (Pareceres CNE/CP 09/2001 e 27/2001 e Res. CNE/CP/ 01 e 02/2002) tem enfatizado a necessidade de cursos específicos para a formação de licenciados, realizados mediante processo autônomo, numa estrutura com identidade própria (art. $7^{\circ}$ da Res. CNE/ $C P$ 01/02), responsabilizando a preocupação prioritária das universidades e de seus docentes para com os bacharelados pelo pouco prestígio e reduzida atenção com que as licenciaturas são contempladas, reduzidas que ficam a uma atuação meramente residual. A ênfase na especificidade da licenciatura, na importância da relação teoria e 
prática pedagógica desde o início do curso, têm levado à defesa da separação dos cursos de licenciatura e bacharelado, os quais se encontram articulados em muitas instituições.

Em meu entender, essa solução é perigosa, levando à constituição de cursos específicos, com vestibulares próprios, o que conseqüentemente acarretará à perda da articulação com os bacharelados. Sem negar a especificidade da licenciatura e a necessidade de constituição de projeto pedagógico próprio, penso que isso não pode se fazer à-custa de perda da articulação com os bacharelados. Na UNESP, instituição onde trabalho, nos poucos casos em que bacharelado e Licenciatura constituem cursos separados, com vestibulares específicos, a relação candidato/vaga é sempre consideravelmente maior para o bacharelado do que para a licenciatura, levando à seleção de alunos menos capazes para a licenciatura e, conseqüentemente, à qualidade inferior de seus cursos e ao seu desprestígio.

Minha experiência de muitos anos como assessora na Pró-Reitoria de Graduação da UNESP leva-me a considerar que, embora os bacharelados e licenciaturas numa dada área do conhecimento tenham objetivos próprios, eles devem supor um certo conjunto de componentes curriculares comuns, com conteúdos qualitativa e quantitativamente semelhantes, ministrados num tronco comum de currículo. Com isso não se perderá a possibilidade de articulação entre as duas modalidades (licenciatura e bacharelado), garantindose para o licenciado nível semelhante quanto aos conteúdos básicos da área. Garante-se também maior flexibilidade, possibilitando-se ao egresso de uma das modalidades o reingresso para integralizar a outra, com o consequiente aproveitamento dos conteúdos básicos já cursados. De outro lado, o currículo específico da licenciatura não pode ser reduzido ao acréscimo de matérias pedagógicas a um currículo desenvolvido em função de outras finalidades. A prática pedagógica intencionalizada para a formação do professor deve estar presente desde o início do curso, permeando toda a formação. Se um candidato a bacharel for contemplado, num primeiro ano de curso, com elementos dessa prática, isso certamente em nada o prejudicará. Afinal o que significa a opção pelo bacharelado senão o preparo básico e preliminar para a pesquisa, para atividades profissionais na 
área e para o magistério superior? Ou vamos continuar negando a condiçào e a identidade de professor para o professor/pesquisador do ensino superior? (Costa et al., 2002)

Em síntese, penso que a identidade e a terminalidade própria da licenciatura não poderão ser ganhas às custas da perda da articulação com os bacharelados, o que, aliás, fere a Res. CNE/CP 01/02, que determina a formação em "processo autônomo, em curso de licenciatura plena, numa estrutura com identidade própria", mas "mantida, quando couber, estreita articulação com institutos, departamentos e cursos de areas específicas". Aliás, a própria ANFOPE, que tanto vem lutando pela profissionalização do professor e por sua formação em cursos específicos, alerta em seu último documento para $o$ "perigo de se ampliar o fosso entre a formação do bacharel e a do licenciado" (ANFOPE 2002).

3) Finalmente, um terceiro ponto que eu destacaria é a importância de não desmobilizar a propósito de reformar. A propósito da história da política educacional brasileira, Evaldo Amaro Vieira (1988) observa que as reformas não reformam, mas desmobilizam eventuais movimentos no campo da educação. Assim, é preciso ter o cuidado de não desativar as instituições públicas de formação de nível médio, antes de garantir a possibilidade de o Estado assegurar oportunidades de formação em nível superior; de não substituir as Faculdades de Educação isoladas por de ISEs que admitam condições menos rigorosas de qualificação do corpo docente; de não desmobilizar currículos considerados excessivamente teóricos ou conteudistas, por um modelo pedagógico que eleja a prática pedagógica como foco formativo, sem a necessária reflexão sobre ela a luz de uma formação teórica sólida. Também é preciso ter cuidado para não esvaziar os cursos regulares de formação, substituindo-os por programas apressados e aligeirados, implementados com auxílio dos recursos da educação à distância. Aliás, a formação à distância, sobretudo para professores em exercício, já está acontecendo em vários Estados do Brasil, cujos programas deixo de comentar, dada minha pouca familiaridade com os mesmos. Menciono apenas o implementado por minha Universidade, a UNESP, em convênio com 84 Prefeituras Munici- 
pais, para mais de 4000 alunos, a título de atender ao art. 87, parágrafo $3^{\circ}$ da LDB, ou seja, com o propósito de ministrar programas de capacitação para professores em exercício. Em que pese ser esse o objetivo do projeto inicial, pergunto-me se não estaríamos apenas oferecendo a oportunidade de realizar um curso de Pedagogia, de padrão inferior ao ministrado regularmente pela Universidade, para todos aqueles que as Prefeituras aceitam como inscritos, independentemente de estarem ou não em exercício de função docente na rede conveniada. Assim, não se trataria de capacitação para professores em exercicio, prevista nas disposições transitórias da Lei, mas de formação inicial para jovens egressos do ensino médio, que deixarão de freqüentar cursos regulares de formação, causando a diminuiçào de sua procura..

Em suma, tomara a conquista principal da nova Lei - qual seja a adoção de uma política unitária e integrada de formação docente para a educação básica, em curso de licenciatura em nível superior - que deveria levar ao fim de diferentes categorias de professores, não se transforme apenas na introdução de novas formas mais sutis de diferenciação entre os cursos, todos formalmente em nível superior, mas na prática de nível tão ou mais diversificado do que antes.

\section{Referências Bibliográficas}

ANDRÉ, Marli, et al. Estado da arte da formação de professores no Brasil. Educação \& Sociedade, Centro de Estudos Educação e Sociedade, ano XX, no 68, p. 301-309, 1999 (Número especial: formação de profissionais da educação: políticas e tendências).

ANFOPE. Base comum nacional para a formação dos profissionais da educação: um projeto ainda em construção. Documento Gerador. XI Encontro Nacional. Florianópolis, 2002.

CANDAU, V. M. Universidade e formaçāo de professores: que rumos tomar? In: CANDAU, V.M. (org.). Magistério: construção cotidiana. Petrópolis: Vozes, 1998, p.51-68.

COSTA, José Fernandes; BIT"TENCOURT', Jane; MEYER, Lucila Mareli 
\& SILVA, Carla Regina. Problemática do Bacharelado e da Licenciatura: o sentido da pesquisa e da formação para a docência. TrabaIho apresentado à $25^{2}$. Reunião Anual da ANPEd, 29/9- 2/10/2002, Caxambu, MG.

FREITAS, Helena C. L. A formação dos profissionais da educação básica em nível superior: desafios para as universidades e faculdades/centros de educação. In: BICUDO, Maria A. V. \& SILVA Jr., Celestino (orgs.). Formação do educador e avaliação educacional: formação inicial e contínua, v.2. São Paulo: Editora UNESP, 1999. p. 103-127.

NUNES, Célia Maria Fernandes. Saberes docentes e formação de professores: um breve panorama da pesquisa brasileira. Educação \& Sociedade, Centro de Estudos Educação e Sociedade, ano XXII, $\mathrm{n}^{\circ}$ 74, p.27-42, abr. 2001.

SILVA, Waldeck C. da. A criação dos institutos superiores de educação no Brasil: alternativa superior para a formação de professores? Trab. Apresentado na 22 Reunião anual da ANPEd, 26-30/9/ 1999, Caxambu, MG.

TANURI, Leonor M. História da formação de professores. Revista Brasileira de Educação, ANPEd, n 14, p. 61-88, mai/jun/jul/ago 2000. (Número especial: 500 anos de educação escolar).

. Política integrada de formação de professores. Cadernos de Pesquisa, Fundação Carlos Chagas, n 71, p. 82-5, nov 1989.

VIEIRA, E.A. Política social e educação. Idéias. São Paulo, nº 1, p. 13-15, 1988.

WEBER, Silke. Como e onde formar professores: espaços em confronto. Educação e Sociedade. São Paulo, ano XXI, nº 70, p.129-155, abr. 2000. 